\title{
Current status of bronchoscopic lung volume reduction with endobronchial valves
}

\author{
Pallav L Shah, ${ }^{1,2,3}$ Felix J F Herth ${ }^{4,5}$
}

\begin{abstract}
${ }^{1}$ The NIHR Respiratory Biomedical Research Unit, Royal Brompton and Harefield NHS Foundation Trust and Imperial College, London, UK ${ }^{2}$ Department of Respiratory Medicine, Chelsea \& Westminster Hospital, London, UK

${ }^{3}$ National Heart \& Lung Institute, Imperial College, London, UK

${ }^{4}$ Department of Pneumology and Respiratory Care Medicine, Thoraxklinik, University of Heidelberg, Heidelberg, Germany

${ }^{5}$ Translational Lung Research Center, Heidelberg, Germany
\end{abstract}

\section{Correspondence to} Dr Pallav L Shah, Royal Brompton Hospital, Sydney Street, London SW3 6NP, UK; pallav.shah@ic.ac.uk

Received 16 April 2013 Revised 28 June 2013 Accepted 14 August 2013 Published Online First 5 September 2013

\section{SLinked d}

- http://dx.doi.org/10.1136/ thoraxjnl-2013-204749

- http://dx.doi.org/10.1136/ thoraxjnl-2013-204875

To cite: Shah $\mathrm{PL}$, Herth FJF. Thorax 2014;69:280-286.

\begin{abstract}
Introduction Chronic obstructive pulmonary disease (COPD) is a major cause of morbidity and mortality worldwide. Emphysema is a component of COPD characterised by hyperinflation resulting in reduced gas exchange and interference with breathing mechanics. Endoscopic lung volume reduction using one-way valves to induce atelectasis of the hyperinflated lobe has been developed and studied in clinical trials over the last decade.

Methods Searches for appropriate studies were undertaken on PubMed and Clinical Trials Databases using the search terms COPD, emphysema, lung volume reduction and endobronchial valves.
\end{abstract}

Results The evidence from the randomised clinical trials suggests that complete lobar occlusion in the absence of collateral ventilation or where there is an intact lobar fissure are the key predictors for clinical success. Other indicators are greater heterogeneity in disease distribution between upper and lower lobes. The proportion of patients that respond to treatment improves from $20 \%$ in the unselected population to $75 \%$ with appropriate patient selection. The safety profile for endobronchial valves in this severely affected group of patients with emphysema was acceptable and the main adverse events observed were an excess of pneumothoraces.

Conclusion Selected patients have the potential of significant benefit in terms of lung function, exercise capacity and possibly even survival. These considerations are essential in-order to maximise patient benefit in a resource-limited environment and also to ensure that beneficial treatments are available for the appropriate patient.

\section{INTRODUCTION}

The World Health Organization estimates that chronic obstructive pulmonary disease (COPD) is the fourth commonest cause of death, and in 2000, 2.74 million people died worldwide from COPD. ${ }^{1}$ Although the statistics for emphysema are less clear, the corresponding estimate for emphysema was over 45000 deaths. Pharmacological therapy is aimed at improving the airway component of COPD and has little effect in patients with a predominantly emphysema phenotype.

Emphysema is abnormal, permanent enlargement of air spaces distal to the terminal bronchioles and the destruction of their walls associated with loss of the elastic connective tissue but without obvious fibrosis. This results in a reduced area for gas exchange and a reduction in the elastic recoil of the lungs. There is airway collapse on expiration, causing increased airflow resistance, which leads to dynamic hyperinflation. The effect is exaggerated during exercise, decreasing the compliance of the chest wall and reducing the functioning of the respiratory muscles. The increased work of breathing results in breathlessness, reduced exercise capacity and reduced quality of life. ${ }^{2-6}$

In addition to the effect on respiratory mechanics, there is evidence to suggest that hyperinflation may also negatively impact cardiac performance. Watz et $a l^{7}$ demonstrated a stronger inverse relationship between cardiac chamber size (measured by echocardiography) and static lung hyperinflation measurements compared with measurements of airway obstruction or diffusion capacity. Hyperinflation also increases intrathoracic pressures and thus reduces venous return, ventricular volumes, and hence left ventricular stroke volume. ${ }^{8}$

Patients with severe emphysema have limited treatment options apart from lung transplantation, which is a very limited resource and in selected patients lung volume reduction surgery (LVRS). The technique of resizing the lung to reduce volume in patients with emphysema was first proposed by Brantigan in $1956 .{ }^{9}$ By resection of emphysematous tissue, the residual volume (RV) is reduced, thereby improving the RV:total lung capacity (TLC) ratio and so allowing the distended chest cavity to become more compliant.

The National Emphysema Treatment Trial was a prospective randomised controlled trial comparing optimal medical treatment with optimal medical treatment plus LVRS. ${ }^{10}$ The results from this study suggested that improvements in functional capacity and survival were limited to a small subgroup of patients with upper lobe predominant disease and low baseline exercise tolerance. These results and the high hospital costs of this procedure fuelled the development of bronchoscopic techniques to induce volume reduction.

The progress of interventional bronchoscopy for emphysema has been far more creative than originally predicted in an editorial by Toma et al. ${ }^{11}$ Techniques such as airway bypass, endoscopic sealant, steam and lung volume reduction coils have been developed. ${ }^{12-19}$ This review focuses on endobronchial valves. This technique has the most extensive evidence base and has been developed over the last decade. ${ }^{20-26}$

The endobronchial valves reduce the flow of air into the treated lobe during inspiration but allow secretions and air to be expelled from that region during expiration. If the valves are able to effectively isolate the lobe then the volume of the lobe would shrink with progressive expiration and eventually completely collapse. The effectiveness of the valves is variable and dependent on operator and 
patient characteristics: correct sizing of the valve, correct placement, pattern of emphysema, presence or absence of accessory ventilatory pathways. In the absence of atelectasis there may be some clinical benefit due to redirection of airflow away from more damaged bullous lung to less damaged areas of lung. In contrast with surgical volume reduction there is actual resection of lung tissue. The reduction in lung volumes improves the elastic recoil of the lung and chest wall dynamics. This in turn improves lung function, quality of life and exercise capacity.

\section{PROCEDURE}

\section{Zephyr valves}

The delivery catheter for the Zephyr valves (Pulmonx, California, USA) has two flanges measuring $5.5 \mathrm{~mm}$ and $8.5 \mathrm{~mm}$. There is also a marker on the catheter tip which indicates the length of the valve in contact with the airway wall (landing zone). The first step is to use these markers on the delivery catheter to determine the size of the valves required in the segments to be occluded and also that there is an adequate 'landing zone' for the valve to sit on. ${ }^{27}$ Incorrectly placed valves are either unlikely to adequately occlude the segment or more likely to be expectorated.

Once the valve size is determined the Zephyr valve is loaded into the catheter and then guided into the desired lobar segment. The valve should be slightly protruded from the delivery catheter and wedged onto the first carina within the segment and then deployed. This ensures that the whole segment is occluded and that the valve has not been inadvertently pushed into a subsegment allowing air into the adjacent segment. However, in the presence of an adequate landing zone, the valve can be placed just distal to the ostium to ensure that all side branches are distal to the valve.

Figure 1A-C shows an example of a correctly and incorrectly placed valve.

\section{Intrabronchial valve}

The intrabronchial valve (IBV) (Spiration/Olympus America, Seattle, Washington, USA) is available in three sizes $(5,6$ and $7 \mathrm{~mm}$ ) and airway sizing is a crucial initial step. A calibrated saline-filled balloon is inserted into the target segment. The balloon is inflated with saline from a calibrated precision syringe $(500 \mu \mathrm{L})$ and the volume required to optimally inflate the balloon to fit the airway segment estimates the size of the segment. The balloon should be moved back and forth in the segment so that the optimal inflation can be gauged. Ideally there should not be excessive impingement to movement and yet the balloon should not slide easily back and forth. Each of the target segments are measured first. ${ }^{28}$

The appropriate size IBV is loaded into the delivery catheter. The catheter is guided into the target segment and the marker, which estimates the position of the valve leaflets aligned with the rim of the airway segment. The valve is deployed into the position. The valve should be checked for optimal sizing and placement. A valve that is too big for the segment may not open fully and may appear ruffled at the edges, whereas a valve that is too small for the airway will migrate distally over time (this may leave an adjacent sub-segmental airway branch patent).

\section{Safety}

The morbidity and mortality associated with LVRS was the main factor that promoted the development of bronchoscopic techniques for volume reduction. Surgery even in the most experienced hands was associated with a 4\% 90-day mortality. ${ }^{29}$ The morbidity was also significant with mean inpatient hospital stay of 13.5 days. Complications were significant as $46 \%$ of patients had a persistent air leak requiring intercostal drainage for more than 7 days, $11 \%$ of patients had pneumonia, $7 \%$ of patients required intubation and mechanical ventilation and $6 \%$ of patients required further surgery.

In contrast, the safety profile for endobronchial valves in this severely affected group of patients with emphysema is considerably more acceptable. In the randomised trials there were four deaths $(1.1 \%)$ in patients treated with endobronchial valves (overall treatment group $\mathrm{n}=362$ ). In the control group there was one death within the first 90 days $(n=183,0.5 \%) .^{24-262830}$ The randomised controlled trials with Zephyr valves ${ }^{24} 25$ reported on a composite event rate of major side effects, which comprise death, respiratory failure, pneumonia distal to the valves, massive haemoptysis, pneumothorax or prolonged air leak for more than 7 days or emphysema. This composite complication rate at 12 months was $10.3 \%$ for patients treated with valves compared with $4.6 \%$ in the control group $(p=0.17)$. As expected, COPD exacerbations were the most common adverse event. The cumulative rates are tabulated for the first 90 days in table 1 .

Pneumothoraces are the main complication directly related to insertion of the valves. The strategy originally used for IBV was complete bilateral treatment of upper lobes and this was associated with a high risk of pneumothoraces and there were three early deaths. The bilateral treatment with complete occlusion was a concern and they then altered their strategy to bilateral incomplete treatment with a subsegment on the right side and the lingual on the left untreated. ${ }^{26} 2830$ There was a significant reduction of pneumothoraces with this technique but also a lower incidence of atelectasis. The clinical implications of this are discussed later. Evolving data suggest that a post-procedure pneumothorax is more likely in patients who develop atelectasis. Conformational changes in the lung with collapse of the treatment lobe and expansion of other areas of the lung may lead to tears in any adherent area of the lung leading to a pneumothorax. An alternative mechanism may be rapid change in elastic recoil altering the tension in any bullous areas of lung, leading to rupture of the bulla and a pneumothorax. These patients derive the greatest benefit in the longer term. ${ }^{31}$ Hence, the main adverse event and clinical benefit appear to be inextricably linked. Pneumothoraces or the development of surgical emphysema following endobronchial valve insertion should be managed by the insertion of a large bore (20-28 gauge) intercostal drain with an underwater seal. A persistent air leak or a high flow leak with respiratory compromise may require the removal of at least one of the endobronchial valves. If this fails to control the air leak in selected patients, video-assisted thoracoscopy and surgery may need to be considered.

\section{Clinical efficacy}

Indiscriminate treatment of patients with severe emphysema with endobronchial valves only results in small clinically insignificant benefits. In the North American cohort of the VENT Study which randomised 321 patients (220 had treatment with valves and 101 were controls), the primary outcome of forced expiratory volume in $1 \mathrm{~s}\left(\mathrm{FEV}_{1}\right)$ only improved by $4.3 \%(95 \%$ CI 1.4 to 7.2$).^{24}$ This equated to a change in $\mathrm{FEV}_{1}$ of a mere $34.5 \mathrm{~mL}$. Other parameters including clinical value also showed minor improvement which would not be considered clinically meaningful; St George's Respiratory Questionnaire (SGRQ, mean decrease of $-2.8, \mathrm{CI}-4.7$ to 1.0$)$ and 6 min walk test (6MWT, mean change of $9.3 \mathrm{~m}$, CI 0.5 to 19.1. Data from the randomised study in Europe, which is identical in design to the North America VENT Study, were similar. ${ }^{25}$ The change in 
A

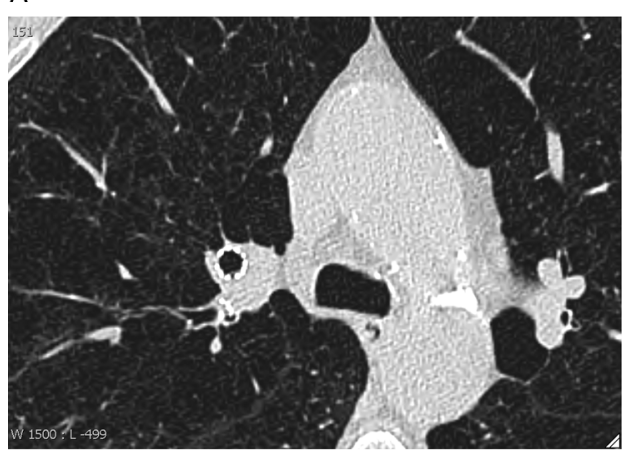

$\mathrm{C}$
B

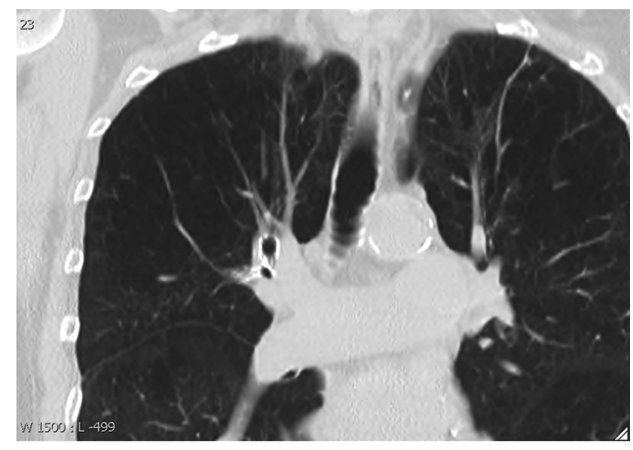

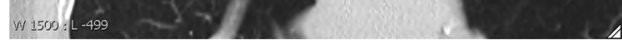

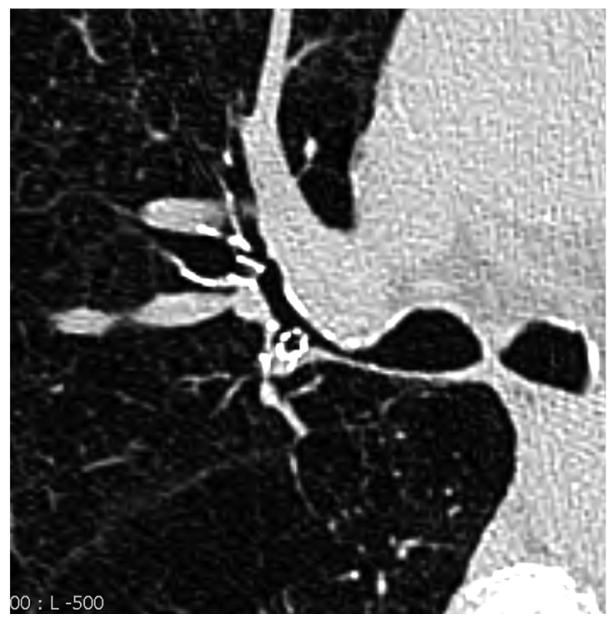

Figure 1 (A) Axial CT scan and (B) coronal section demonstrating Zephyr valve in a good position in the right upper lobe and (C) Zephyr valve poorly positioned in posterior segment of the right upper lobe where a patent adjacent segment is visible on the axial CT scan.

FEV $_{1}(7 \pm 20$ absolute $\%$ change $)$ with SGRQ reduction of $-5( \pm 1.4)$ and $6 \mathrm{MWT}$ improvement of $15 \mathrm{~m}( \pm 91)$. Although, the overall benefits are small there were subgroups of patients who showed remarkable responses with improvements in $\mathrm{FEV}_{1}$ of over $20 \%$. In this subgroup of patients there were corresponding clinically significant improvements in exercise capacity and quality of life.

The early case series yielded similar results with some patients developing a marked benefit with improvements in exercise capacity and pulmonary function. These improvements were generally

Table 1 Percentage of patients experiencing adverse events at 90 days in the randomised clinical trials

\begin{tabular}{lcc}
\hline & Treatment & Control \\
\hline Death & 0.8 & 0.6 \\
COPD exacerbation with hospitalisation & 9.2 & 4.8 \\
COPD exacerbation without hospitalisation & 10.5 & 15.7 \\
Infection & 1.2 & 0 \\
Respiratory failure & 2.2 & 0.7 \\
Pneumonia distal to valve & 1.9 & - \\
Pneumonia other lobe & 2.8 & 2.0 \\
Haemoptysis: massive & 0.6 & 0 \\
Pneumothorax: $>7$ days & 2.2 & 0 \\
Emphysema & 0 & 0 \\
\hline Data derived from Sciurba et al ${ }^{24}$ Herth et al ${ }^{25}$ and Ninane et al. ${ }^{26}$ & \\
COPD, chronic obstructive pulmonary disease. & &
\end{tabular}

observed in patients who had developed lobe atelectasis. Potential factors explaining why a significant proportion of patients do not develop lobar atelectasis are technical, anatomical or related to disease morphology. Technical factors are operator dependent with incomplete occlusion of the lobe due to inadequate seal or a side branch that has been left patent (figure 1). Of note, only 162 of 331 treated patients (48.9\%) in both VENT cohorts achieved lobar exclusion.

The presence of collateral ventilation due to interlobular channels is another factor that determines success. The channels vary from the pores of Kohn to alveolar ducts described by Lambert and accessory communication between terminal bronchioles described by Martin. ${ }^{32-35}$ These alternative pathways allow backfilling of the lobe and ensure that ventilation of the lobe is maintained albeit at a lower extent despite occlusion of the lobe with endobronchial valves. Furthermore, the destructive process of emphysema also breaks down the barriers between the lobes of the lung. This latter mechanism is likely to be a dominant factor as the pores and channels are likely to be low flow channels. Hence in an individual patient the integrity of the inter-lobar fissure is likely to be a predictor for success of endobronchial valve therapy. Figure 2 is an example of a patient with an incomplete major fissure on the right side and an intact fissure on the left side.

The two randomised studies with the Zephyr endobronchial valves also evaluated outcome based on the integrity of the interlobar fissures. ${ }^{24} 25$ The results indicated that patients with an intact fissure (more than $90 \%$ intact as judged by thin slice CT scans) were more likely to benefit from endobronchial 


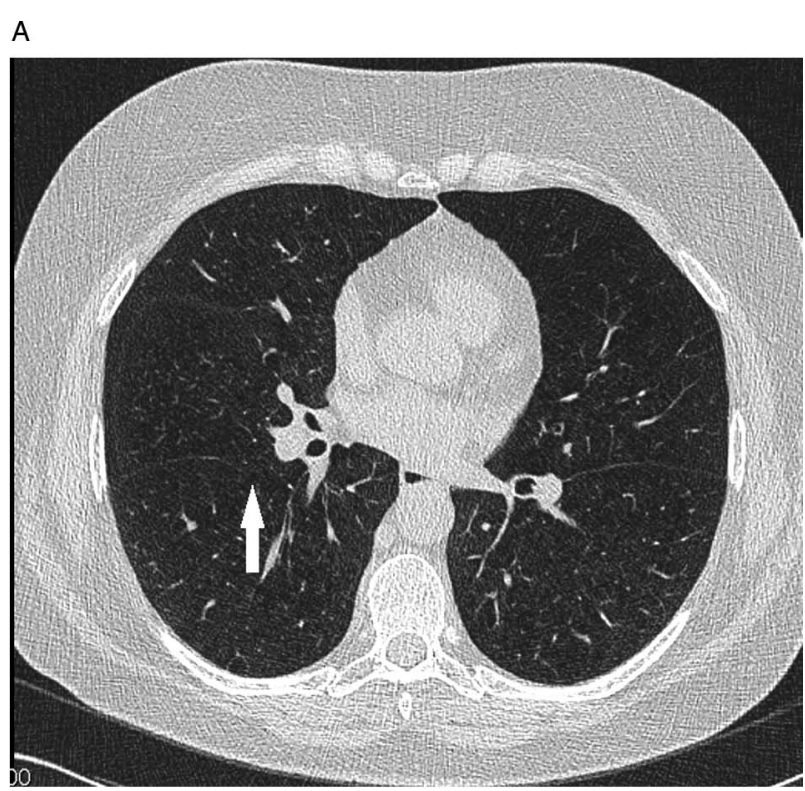

B

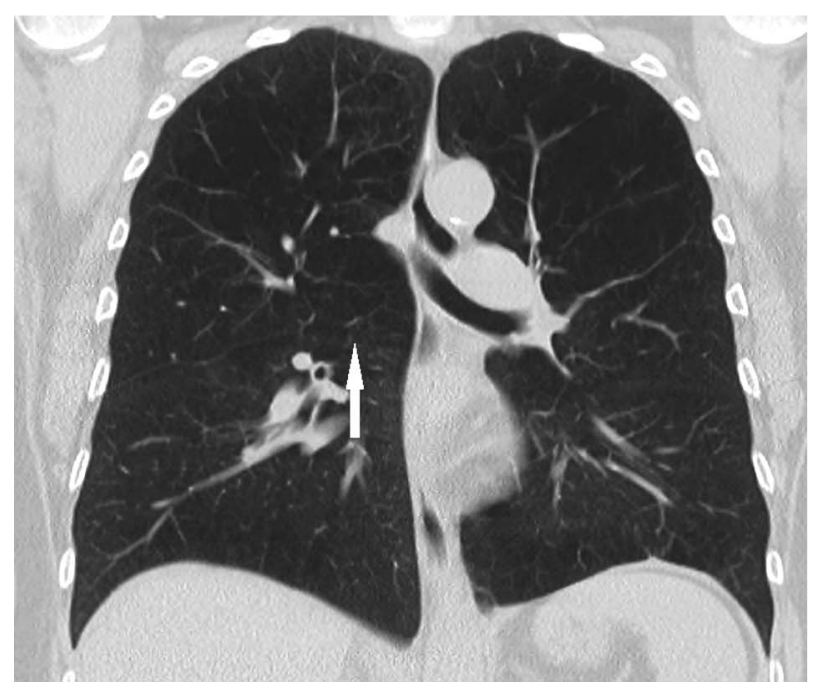

Figure 2 (A) Axial and (B) coronal CT scans with arrow demonstrating a disrupted fissure in the right lung.

valves. Only 123 of 331 treated patients in both VENT cohorts had complete fissures (37.1\%).

Table 2 Changes in outcome measurements from baseline according to fissure integrity and correct valve placement to achieve complete occlusion

\begin{tabular}{|c|c|c|c|c|c|c|}
\hline & \multicolumn{2}{|l|}{$\mathrm{FEV}_{1}$} & \multicolumn{2}{|l|}{ SGRQ } & \multicolumn{2}{|c|}{$\begin{array}{l}\text { Cycle } \\
\text { ergometry (W) }\end{array}$} \\
\hline & Valves (\%) & Control (\%) & Valves & Control & Valves & Control \\
\hline Overall & $7 \pm 20$ & $0.5 \pm 19$ & $-5 \pm 14$ & $0.3 \pm 13$ & $2 \pm 14$ & $-3 \pm 10$ \\
\hline $\begin{array}{l}\text { Intact } \\
\text { fissures }\end{array}$ & $16 \pm 21$ & $2 \pm 14$ & $-6 \pm 15$ & $3 \pm 15$ & $4 \pm 1$ & $-3 \pm 7$ \\
\hline $\begin{array}{l}\text { Intact fissure } \\
\text { and correct } \\
\text { placement }\end{array}$ & $26 \pm 24$ & $3 \pm 14$ & $-10 \pm 15$ & $3 \pm 15$ & $8 \pm 15$ & $-3 \pm 7$ \\
\hline
\end{tabular}

Data derived from Herth et al..$^{25}$

$\mathrm{FEV}_{1}$, forced expiratory volume in $1 \mathrm{~s}$; SGRQ, St George's Respiratory Questionnaire.
In the European study only a third of patients were judged as having an intact inter-lobar fissure. At 6 months the mean percent change in $\mathrm{FEV}_{1}$ was $16 \pm 21(\mathrm{n}=44)$ in patients with a complete fissure who had valves inserted compared with $1 \pm 18$ $(n=67)$ in treated patients with an incomplete fissure. Changes in the respective control groups were $2 \pm 14$ and $-1 \pm 21$. Furthermore, patients with an intact fissure who had correctly placed valves with complete occlusion derived an even greater benefit at 6 months (mean percent change in $\mathrm{FEV}_{1}$ was $26 \pm 24$ $(\mathrm{n}=20)$ table 2 .

The importance of complete occlusion has been further demonstrated by the lack of benefit in a randomised study in which patients were randomised to either incomplete bilateral occlusion with the IBV or to a sham bronchoscopy. ${ }^{26}$ Although there was measurable volume reduction in the treated lobe there was no difference in the changes to quality of life, lung function or exercise capacity in comparison to the sham group. There was also no appreciable difference in these measurements in comparison to the baseline measurements.

A small randomised study with the IBV where patients were randomised to either complete or incomplete lobar occlusion provided further evidence that the differences were due to treatment strategy and not valve choice. ${ }^{36}$ Seven of the 11 patients who were treated by complete occlusion had radiological evidence of atelectasis whereas none of the patients (0 of 11) treated by incomplete bilateral occlusion had any atelectasis. The group with unilateral complete treatment also had improvements in $\mathrm{FEV}_{1}$ of $21.4 \%$, increase in $6 \mathrm{MWT}$ by $48.9 \mathrm{~m}$ and a reduction in SGRQ by 11.8 points, whereas patients with incomplete occlusion had the following respective results: change from baseline in $\mathrm{FEV}_{1}$ of $-24 \%$, decline in $6 \mathrm{MWT}$ by $52.3 \mathrm{~m}$ and a worsening in SGRQ by 2.1 points.

\section{Measurement of collateral ventilation}

One of the major limitations of evaluating fissures on CT scans by the human eye is its subjective nature and inconsistency in quantifying the degree of integrity. In a recent published paper CT scans from a cohort of patients with emphysema were evaluated by a respiratory physician, experienced chest radiologist and a general radiologist with a poor correlation of the results. $^{37}$

Vida Diagnostics has developed semi-automated software which evaluates the integrity of the fissure on a thin slice CT scan (figure 3). This system may be more accurate than simply visually determining the integrity of the fissure but does require some specialist input to check that the automated software has identified the correct structures. Furthermore, the lobar volumes can be accurately estimated and change in lobar volumes following treatment measured. However, at this time, the quantification of the completeness of the fissure as determined by the software and its accuracy in predicting volume reduction has not been prospectively validated.

The Chartis system (Pulmonx) is a commercially available system, which allows collateral ventilation to be measured during bronchoscopy. It consists of a balloon catheter and console which houses the flow and pressure sensors. The catheter is inserted into the origin of the target lobe and the balloon inflated so as to completely isolate that lobe. Airflow is measured through the sensors in the console. Gradual decline in expiratory flow after balloon occlusion suggests that there is an absence of collateral ventilation (figure 4A) whereas the persistence of flow after $5 \mathrm{~min}$ of balloon inflation particularly where more than a litre of air has been expelled suggests the presence of significant collateral ventilation (figure 4B). There are some 


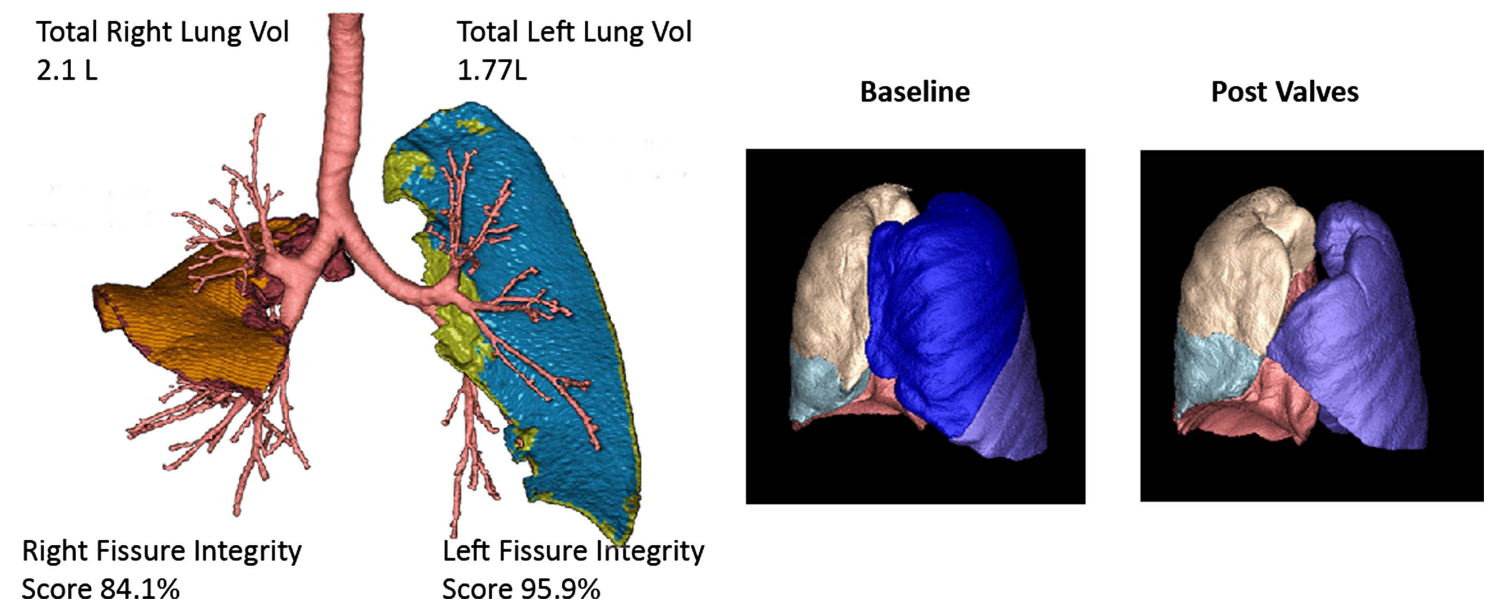

Figure 3 Software analysis of fissure integrity and lobar lung volumes (courtesy of VIDA Diagnostics).

situations when there may be low flow collateral channels where the flow is diminished but maintained well over $5 \mathrm{~min}$.

The value of the Chartis system has been studied prospectively in a large case series involving seven centres in Europe. ${ }^{37} 38$ Patients were classified into two groups according to the presence or absence of collateral ventilation in a treatment lobe. The Chartis system was used to determine collateral ventilation status prior to insertion of endobronchial valves in the target lobe. Fifty-one patients were determined as having no collateral ventilation and 29 had evidence of collateral ventilation in the treatment lobe. There was a much greater volume reduction, a median of $753 \mathrm{~mL}$ and a mean percentage increase in $\mathrm{FEV}_{1}$ of $16 \%$ in the group without collateral ventilation. However, the group with collateral ventilation had a minimal change in lung volume (median of $99 \mathrm{~mL}$ ) and an increase in $\mathrm{FEV}_{1}$ of only $1 \%$. In a subgroup from this case series the patients were classified according to the integrity of the lobar fissure and separately classified according to the collateral ventilation status as determined by the Chartis system. ${ }^{39}$ The accuracy in predicting a responder was similar irrespective of the method used to classify collateral ventilation status (74\%). The two analyses matched in 48 out of 70 patients and in this scenario the response rate was $88 \%$.
Heterogeneity was another parameter that was associated with a greater likelihood to increase benefit. The subgroup analysis from the two studies with Zephyr valves suggests that patients with greater heterogeneity as measured on the CT scans (ratio of destruction between the target and ipsilateral lobe) had a greater benefit than those with a lower heterogeneity index. ${ }^{24} 25$ This would be logical as in patients with heterogeneous emphysema there is some better quality lung pulmonary tissue to benefit from the improved respiratory dynamics following atelectasis of the more damaged areas. However, more research is required in this area since there are limited options for patients with homogeneous emphysema. ${ }^{12}$ In the VENT trial the percentage improvement in $\mathrm{FEV}_{1}$ in the 6-15\% heterogeneity subgroup was the same as the $15-25 \%$ subgroup $^{24}$ and the threshold of $15 \%$, chosen for defining high heterogeneity, was purely based on the median heterogeneity of the treatment group. Furthermore, in the Chartis study, of the 20 collateral ventilation negative patients with a low heterogeneity score, $14(70 \%)$ achieved a TLVR of $\geq 350 \mathrm{~mL}$, which might suggest that the mechanical aspects of volume reduction may be dependent on $\mathrm{CV}$ and complete lobar exclusion rather than heterogeneity. This is consistent with previous LVRS results, ${ }^{40}$ which concluded that

A

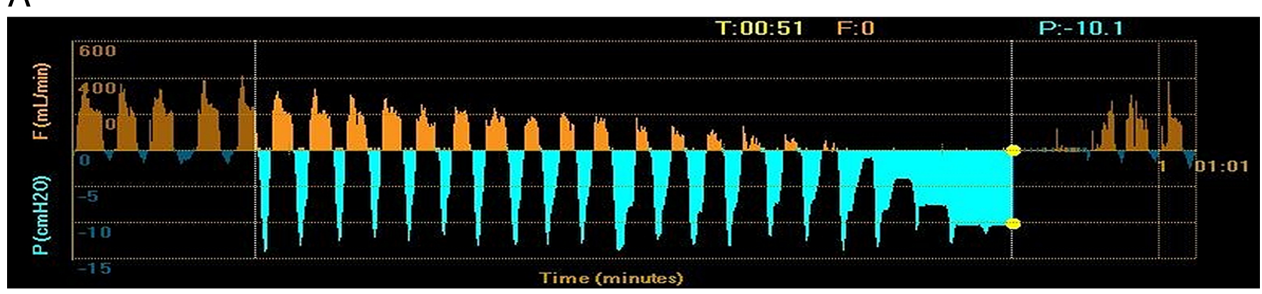

B

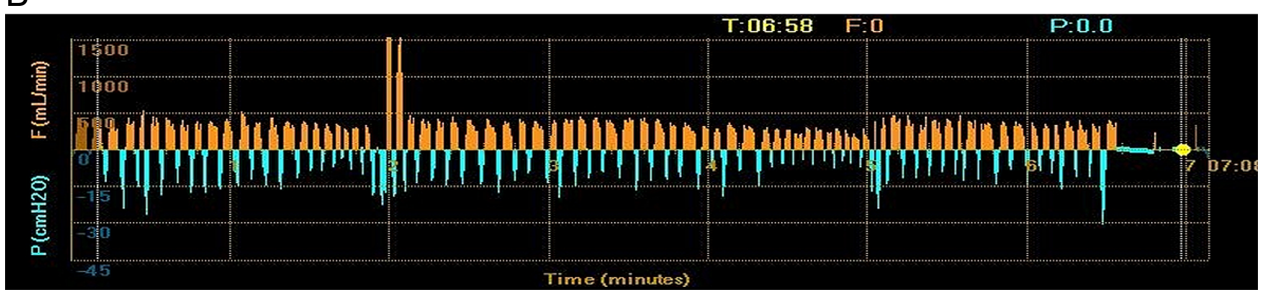

Figure 4 (A) Chartis output demonstrating a reduction in expiratory airflow but maintenance of inspiratory pressure following balloon occlusion of the treatment lobe indicating the absence of collateral ventilation. (B) Chartis output demonstrating maintenance in expiratory airflow following balloon occlusion of the treatment lobe, indicating the presence of collateral ventilation. 
Table 3 Baseline characteristics of the patients enrolled in the various trials

\begin{tabular}{|c|c|c|c|c|c|c|c|}
\hline Inclusion criteria & NETT & NETT responder & VENT2 & IBV & RESET & Sealant & Steam \\
\hline Age (years) & $40-74$ & 67 & 63.4 & 65 & 62 & 64 & 63 \\
\hline Emphysema distribution & All & UL & UL & UL & All & UL & UL \\
\hline $\mathrm{FEV}_{1} \%$ & $20-45$ & 25 & 30 & 31 & 27 & 31 & 31 \\
\hline $\mathrm{RV} \%$ & $>150$ & 223 & 216 & 221 & 236 & 238 & 237 \\
\hline $\mathrm{paO2}(\mathrm{kPa})$ & $>6$ & 8.5 & 9.2 & 9.1 & - & 8.7 & 8.5 \\
\hline $\mathrm{paCO} 2(\mathrm{kPa})$ & $<6.7$ & 5.7 & 5.5 & 5.5 & - & 5.1 & 5.3 \\
\hline $\begin{array}{l}\text { 6MWD } \\
\text { (m) }\end{array}$ & $>140$ & 328 & 333 & 337 & 293 & 293 & 300 \\
\hline
\end{tabular}

6MWD, 6 min walking distance in metres; $\mathrm{FEV}_{1} \%$, forced expiratory volume in $1 \mathrm{~s}$ percent predicted; IBV, intrabronchial valve; LL, lower lobe predominant emphysema; LVRC, lung volume reduction coil; NETT, National Emphysema Treatment Trial; paCO2, partial pressure of carbon dioxide in kilopascals; paO2, partial pressure of oxygen in kilopascals; RV, residual volume percent predicted; UL, upper lobe predominant emphysema.

patients with homogeneous emphysema should not unvaryingly be excluded from surgery.

The results for longer-term follow-up patients who had been treated over 5 years ago suggest some survival benefit in patients who achieve atelectasis. The five patients from the Royal Brompton cohort $(n=19)$ who developed atelectasis were still alive 6 years after treatment with endobronchial valves whereas 8 of 14 patients without atelectasis had died. ${ }^{41}$ Similar results were published by Venuta et al ${ }^{42}$ for 33 patients with longer follow-up in whom the survival differences between groups with complete and incomplete fissures were significant.

Endobronchial valves have also been used with some success to induce lung volume reduction in specific patient groups. A case series of six patients with $\alpha-1$ antitrypsin deficiency with the $\mathrm{ZZ}$ phenotype who were referred for lung transplantation assessment showed an improvement in median $\mathrm{FEV}_{1}$ of $0.58-0.91 \mathrm{~L} / \mathrm{s}$, an improvement in RV/TLC ratio (from 0.74 to 0.58 ) and a statistically significant improvement in the lung allocation score following endobronchial valve treatment. ${ }^{43}$ In fact, three patients improved to a degree that they did not fulfil the criteria for active transplant listing. Similarly, another case series ${ }^{44}$ of four patients awaiting lung transplantation reported objective improvements which allowed three out of the four patients to successfully survive until surgery. Given the shortage of organs and waiting times for transplantation, this therapy may be considered a bridging option to transplantation in the future.

Valves have also been successfully used to treat acute and chronic hyperinflation in the native lung following single lung transplantation. These patients on immunosuppressants and anti-rejection medications have limited surgical options and the use of endobronchial valves to collapse the hyperinflated native lung enables the continued practice of single lung transplantation, which is key in increasing the availability of limited donor lungs. ${ }^{45-47}$

The baseline characteristics of successfully treated patients from the current evidence base for lung volume reduction (table 3) suggest patients should be selected using the following criteria: significant hyperinflation, RV of $200 \%$ predicted, $\mathrm{FEV}_{1}$ less than $45 \%$ predicted on maximal medical treatment including previous treatment with pulmonary rehabilitation. Determination of the emphysema phenotype from the CT scans is also important.

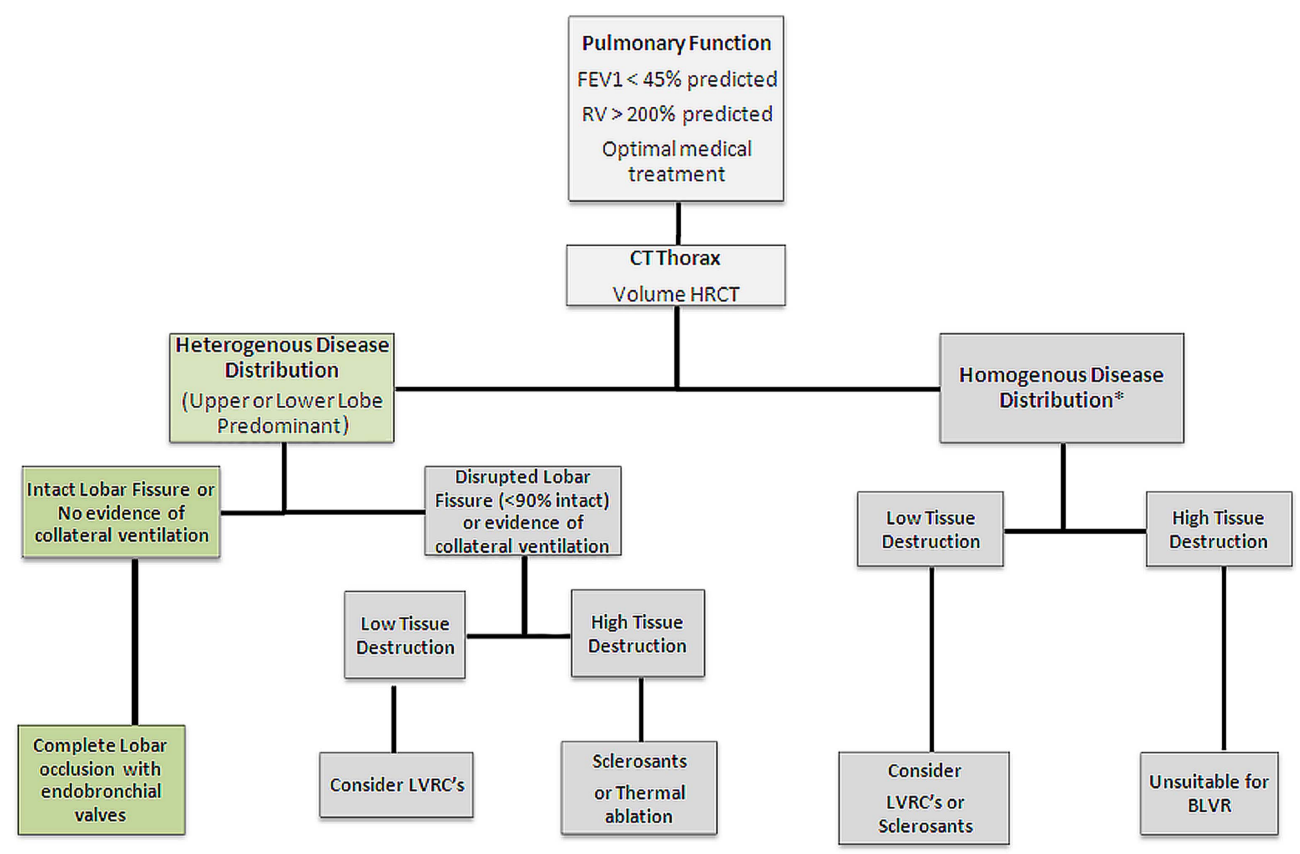

Figure 5 Algorithm for bronchoscopic lung volume reduction in patients with severe emphysema. BLVR, biological lung volume reduction; $\mathrm{FEV}_{1}$, forced expiratory volume in $1 \mathrm{~s}$; HRCT, high-resolution CT; LVRC, lung volume reduction coil; RV, residual volume. 
Patients with predominantly paraseptal emphysema or with a pattern where there is fine permeative disease with a significant small airway component are unlikely to respond. Those with heterogeneous disease and an intact interlobar fissure (over 90\% intact) may be considered for treatment (figure 5) However, at this time, the quantification of the completeness of the fissure as determined by the software and its accuracy in predicting volume reduction or rejecting candidates who might potentially benefit after endobronchial valve therapy has not been prospectively validated. We would also recommend restricting treatment to selected regional or national centres to concentrate expertise, maximise knowledge on patient selection and procedural expertise. This will facilitate further research and development.

In essence, the current evidence does not support indiscriminate treatment of patients with severe emphysema with endobronchial valves. Nevertheless selected patients have the potential of significant benefit in terms of lung function, exercise capacity and possibly even survival. A number of randomised controlled trials are currently underway in North America, Europe and the UK evaluating treatment in a more selected group of patients with emphysema who have heterogeneous disease and an intact lobar fissure.

Contributors This paper was jointly written by PLS and FJFH.

Competing interests PLS and FJFH have participated in some of the clinical trials discussed in this review and the host institutions have been reimbursed for clinical trial expenses.

Provenance and peer review Commissioned; externally peer reviewed.

\section{REFERENCES}

1 WHO. Noncommunicable diseases. http://www.who.int/mediacentre/factsheets/ fs355/en/index.html (accessed 25 Aug 2013)

2 Casanova C, Cote C, de Torres JP, et al. Inspiratory-to-total lung capacity ratio predicts mortality in patients with chronic obstructive pulmonary disease. Am J Respir Crit Care Med 2005;171:591-7.

3 Clanton $\mathrm{TL}$, Levine $\mathrm{S}$. Respiratory muscle fiber remodeling in chronic hyperinflation: dysfunction or adaptation? J Appl Physiol 2009;107:324-35.

4 Baraldo S, Turato G, Saetta M. Pathophysiology of the small airways in chronic obstructive pulmonary disease. Respiration 2012;84:89-97.

5 McDonough JE, Yuan R, Suzuki M, et al. Small-airway obstruction and emphysema in chronic obstructive pulmonary disease. N Engl J Med 2011;365:1567-75.

6 Hackx M, Bankier AA, Gevenois PA. Chronic obstructive pulmonary disease: CT quantification of airways disease. Radiology 2012;265:34-48.

7 Watz $\mathrm{H}$, Waschki B, Meyer $\mathrm{T}$, et al. Decreasing cardiac chamber sizes and associated heart dysfunction in COPD: role of hyperinflation. Chest 2010;138:32-8.

8 Barr RG, Bluemke DA, Ahmed FS, et al. Percent emphysema, airflow obstruction, and impaired left ventricular filling. N Engl J Med 2010;362:217-27.

9 Brantigan OC, Mueller E. Surgical treatment of pulmonary emphysema. Am Surg 1957;23:789-804.

10 Fishman A, Martinez F, Naunheim K, et al. A randomized trial comparing lung-volume-reduction surgery with medical therapy for severe emphysema. $N$ Engl J Med 2003;348:2059-73.

11 Toma TP, Hopkinson NS, Hillier J, et al. Bronchoscopic volume reduction with valve implants in patients with severe emphysema. Lancet 2003;361:931-3.

12 Shah PL, Slebos DJ, Cardoso PF, et al. Bronchoscopic lung-volume reduction with Exhale airway stents for emphysema (EASE trial): randomised, sham-controlled, multicentre trial. Lancet 2011;378:997-1005.

13 Herth FJ, Gompelmann D, Stanzel F, et al. Treatment of advanced emphysema with emphysematous lung sealant (AeriSeal $($ ). Respiration 2011;82:36-45.

14 Kramer MR, Refaely $\mathrm{Y}$, Maimon N, et al. Bilateral endoscopic sealant lung volume reduction therapy for advanced emphysema. Chest 2012;142:1111-17.

15 Gompelmann D, Heussel CP, Eberhardt R, et al. Efficacy of bronchoscopic thermal vapor ablation and lobar fissure completeness in patients with heterogeneous emphysema. Respiration 2012;83:400-6.

16 Herth FJ, Ernst A, Baker KM, et al. Characterization of outcomes 1 year after endoscopic thermal vapor ablation for patients with heterogeneous emphysema. Int J Chron Obstruct Pulmon Dis 2012;7:397-405.

17 Snell G, Herth FJ, Hopkins P, et al. Bronchoscopic thermal vapour ablation therapy in the management of heterogeneous emphysema. Eur Respir J 2012;39:1326-33.
18 Slebos DJ, Klooster K, Ernst A, et al. Bronchoscopic lung volume reduction coil treatment of patients with severe heterogeneous emphysema. Chest 2012:142:574-82.

19 Shah PL, Zoumot Z, Singh S, et al. Randomised control trial of endobronchial coils for the treatment of severe emphysema with hyperinflation (RESET). Lancet Respir 2013;1:233-40

20 Hopkinson NS, Toma TP, Hansell DM, et al. Effect of bronchoscopic lung volume reduction on dynamic hyperinflation and exercise in emphysema. Am J Respir Crit Care Med 2005:171:453-60.

21 Venuta F, de Giacomo T, Rendina EA, et al. Bronchoscopic lung-volume reduction with one-way valves in patients with heterogenous emphysema. Ann Thorac Surg 2005:79:411-16.

22 Snell Gl, Holsworth L, Borrill ZL, et al. The potential for bronchoscopic lung volume reduction using bronchial prostheses: a pilot study. Chest 2003;124:1073-80.

23 Wan IY, Toma TP, Geddes DM, et al. Bronchoscopic lung volume reduction for end-stage emphysema: report on the first 98 patients. Chest 2006;129:518-26.

24 Sciurba FC, Ernst A, Herth FJ, et al. A randomized study of endobronchial valves for advanced emphysema. N Engl J Med 2010;363:1233-44.

25 Herth FJ, Noppen M, Valipour A, et al. Efficacy predictors of lung volume reduction with Zephyr valves in a European cohort. Eur Respir J 2012;39:1334-42.

26 Ninane V, Geltner C, Bezzi M, et al. Multicentre European study for the treatment of advanced emphysema with bronchial valves. Eur Respir J 2012;39:1319-25.

27 Gasparini S, Zuccatosta L, Bonifazi M, et al. Bronchoscopic treatment of emphysema: state of the art. Respiration 2012;84:250-63.

28 Sterman DH, Mehta AC, Wood DE, et al. A multicenter pilot study of a bronchial valve for the treatment of severe emphysema. Respiration 2010;79:222-33.

29 Yusen RD, Lefrak SS, Gierada DS, et al. A prospective evaluation of lung volume reduction surgery in 200 consecutive patients. Chest 2003;123:1026-37.

30 Wood DE, McKenna RJ Jr, Yusen RD, et al. A multicenter trial of an intrabronchial valve for treatment of severe emphysema. J Thorac Cardiovasc Surg 2007;133:65-73

31 Gompelmann D, Eberhardt R, Slebos DJ, et al. Pneumothorax as a predictor of beneficial outcome following endoscopic lung volume reduction. Eur Respir $J$ 2012:40(Suppl. 56):2945s

32 Kohn HN. Zur Histologie des indurirenden fibrinogen pneumonia. Mǘnch Med Woch 1893:40:42-5.

33 Lambert MW. Accessory bronchiolealveolar communications. J Pathol Bacteriol 1955:70:311-14

34 Martin HB. Respiratory bronchioles as the pathway for collateral ventilation. J App/ Physiol 1966;2:1443-7.

35 Gompelmann D, Eberhardt R, Herth FJ. Collateral ventilation. Respiration 2013;85:515-20.

36 Eberhardt R, Gompelmann D, Schuhmann M, et al. Complete unilateral versus partial bilateral endoscopic lung volume reduction in patients with bilateral lung emphysema. Chest 2012;142:900-8.

37 Koenigkam-Santos M, Puderbach M, Gompelmann D, et al. Incomplete fissures in severe emphysematous patients evaluated with MDCT: incidence and interobserver agreement among radiologists and pneumologists. Eur J Radiol 2012; 81:4161-6.

38 Gompelmann D, Eberhardt R, Michaud G, et al. Predicting atelectasis by assessment of collateral ventilation prior to endobronchial lung volume reduction: a feasibility study. Respiration 2010;80:419-25.

39 Herth FJ, Eberhardt R, Gompelmann D, et al. Radiological and clinical outcomes of using Chartis ${ }^{\mathrm{TM}}$ to plan endobronchial valve treatment. Eur Respir $J$ 2013;41:302-8

40 Weder W, Tutic M, Lardinois D, et al. Persistent benefit from lung volume reduction surgery in patients with homogeneous emphysema. Ann Thorac Surg 2009:87:229-37.

41 Hopkinson NS, Kemp SV, Toma TP, et al. Atelectasis and survival after bronchoscopic lung volume reduction for COPD. Eur Respir J 2011;37:1346-51.

42 Venuta $F$, Anile M, Diso D, et al. Long-term follow-up after bronchoscopic lung volume reduction in patients with emphysema. Eur Respir J 2012;39:1084-9.

43 Tuohy MM, Remund KF, Hilfiker R, et al. Endobronchial valve deployment in severe $\alpha-1$ antitrypsin deficiency emphysema: a case series. Clin Respir J 2013;7:45-5.

44 Venuta $F$, Diso D, Anile $M$, et al. Bronchoscopic lung volume reduction as a bridge to lung transplantation in patients with chronic obstructive pulmonary disease. Eur J Cardiothorac Surg 2011:39:364-7.

45 Kemp SV, Carby M, Cetti EJ, et al. A potential role for endobronchial valves in patients with lung transplant. J Heart Lung Transplant 2010;29:1310-12.

46 Pato 0 , Rama $\mathrm{P}$, Allegue $\mathrm{M}$, et al. Bronchoscopic lung volume reduction in a single-lung transplant recipient with natal lung hyperinflation: a case report. Transplant Proc 2010:42:1979-81.

47 Crespo MM, Johnson BA, McCurry KR, et al. Use of endobronchial valves for native lung hyperinflation associated with respiratory failure in a single-lung transplant recipient for emphysema. Chest 2007;131:214-6. 